\title{
Role of Imaging in the Evaluation of Minimal Residual Disease in Multiple Myeloma Patients
}

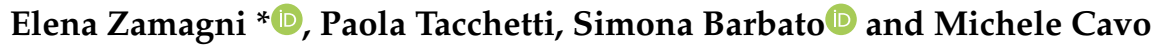 \\ Dipartimento di Medicina Specialistica, Diagnostica e Sperimentale, Istituto di Ematologia "Seràgnoli", \\ Università degli Studi, Azienda Ospedaliero-Universitaria di Bologna, 40138 Bologna, Italy; \\ paola.tacchetti2@unibo.it (P.T.); simona.barbato3@unibo.it (S.B.); michele.cavo@unibo.it (M.C.) \\ * Correspondence: e.zamagni@unibo.it; Tel.: +39-051-2143831; Fax: +39-051-6364037
}

Received: 29 September 2020; Accepted: 29 October 2020; Published: 31 October 2020

\begin{abstract}
The International Myeloma Working Group (IMWG) recently introduced the evaluation of minimal residual disease (MRD) within the multiple myeloma (MM) response criteria, and MRD negativity assessed inside and outside the bone marrow is currently considered the most powerful predictor of favorable long-term outcomes. However, MRD evaluation has thus far relied on flow-cytometry or molecular-based methods, despite the limitations associated with the patchy infiltration of bone marrow (BM) plasma cells and the presence of extra-medullary (EMD). On the contrary, imaging-based sensitive response assessment through the use of functional rather than morphological whole-body (WB) imaging techniques, such as positron emission tomography with computed tomography (PET/CT) and magnetic resonance imaging (MRI), likely is a promising strategy to overcome these limitations in evaluating response to therapy and in the assessment of the MRD status in MM patients. However, despite the significant advances in the development and availability of novel functional imaging techniques for MRD evaluation, a worldwide standardization of imaging criteria for acquisition, interpretation, and reporting is yet to be determined and will be object of future investigations.
\end{abstract}

Keywords: PET/CT; MRI; myeloma; prognosis; minimal residual disease

\section{Imaging for Minimal Residual Disease (MRD) Evaluation}

In 2016, the International Myeloma Working Group (IMWG) formally introduced the evaluation of minimal residual disease (MRD) within the multiple myeloma (MM) response criteria [1]. MRD is usually assessed in the bone marrow (BM) by means of cellular-based (flow-cytometry) or molecular-based (next-generation sequencing) methods. Since plenty of data correlate the depth of response with long-term outcomes, information on MRD may represent a valid and early biomarker for the efficacy of treatment [2]. However, BM plasma cell (BMPCs) infiltration is often irregular, likely increasing the probability of a false-negative evaluation by using techniques relying on $\mathrm{BM}$ specimens-by nature limited to a very small area of the body—with no identification of extra-medullary (EMD) escape in case of metastasis [3]. This phenomenon is currently quite frequent, likely depending on extended overall survival (OS) and the increasingly massive use of functional imaging techniques, and usually culminates in a fatal clinical outcome, despite the progress made with novel therapeutic approaches [3-6].

Besides the patchy infiltration of BMPCs and the presence of EMD, recent prospective studies monitoring patients with serial functional imaging and focal lesion (FL) biopsies have demonstrated that $\mathrm{MM}$ implies a great spatial heterogeneity which is proportional to the size of a FL, and different disease clones with different genomic profiles may coexist in BM and FLs [7,8]. 
For the longest time, imaging in myeloma was based on skeletal survey and limited at staging or re-staging to determine myeloma bone disease. However, this technique is not very sensitive, partly because the healing of bone is limited [9], but also because it is ineffective on soft tissues/masses, being therefore unusable in assessing response to therapy. In such cases, morphological whole-body (WB) imaging techniques should be replaced by functional evaluations, such as positron emission tomography with computed tomography (PET/CT) and magnetic resonance imaging (MRI), both providing a global representation of the tumor burden beyond osteolytic lesions and showing further prognostic markers such as EMD [10]. Patients carrying soft plasmacytomas, either extra-medullary (5-10\% at diagnosis, higher percentage in the later phases of the disease) or paramedullary (20-30\%), more often display a discrepancy between the presence of EM sites of clonal proliferating PCs upon BM MRD negativity [11].

\section{18F-FDG-PET/CT}

One of the best imaging techniques by which to assess tumor metabolic activity and determine treatment efficacy is ${ }^{18}$ Fluorine-fluoro-deoxyglucose (18F-FDG) PET/CT [12,13]. The wide use of this tool mostly relies on its capability of distinguishing between active and inactive (e.g., fibrotic) disease and by the fact that low-dose CT, typically associated with FDG-PET for localization, can precisely map the sites of bone and extra-medullary disease [12].

\subsection{Methods and Standardization}

Largely used worldwide to evaluate and monitor metabolic response to therapy, the 18-FDG $\mathrm{PET} / \mathrm{CT}$ technique is quite standard. With 18F-FDG as the most used tracer, whose dose administration slightly varies based on the system and on the patient's weight, image acquisition and reconstruction follow standard procedures, as well as patient preparation [12], with a total procedure time of approximately 80-90 min. At least the skull, upper limbs, and femurs should be included in the field of view (FOV) of 18F-FDG PET/CT, extended to the lower limbs under certain circumstances. The attenuation, correction, and interpretation of the image are achieved by CT at low doses $(120 \mathrm{kV}$, $80 \mathrm{~mA}$ ). Hypermetabolic bone lesions, irrespective of underlying lytic lesions at $\mathrm{CT}$, are identified with a PET standard spatial resolution limit of approximately $5 \mathrm{~mm}$, even in patients with kidney disease and/or metallic bone implants. Multiplanar cuts are obtained through an ad hoc workstation upon image reconstruction.

Image interpretation typically relies on the standardized uptake value (SUV) maximum (max), especially to evaluate the efficacy of therapy after treatment. This is a semi-quantitative index, traditionally indexed to the background on L1/L2, if healthy; the liver; the spleen; or the mediastinal blood pool (MBP). However, there is as yet no standardization for scan evaluation in MM. Besides this, some other parameters may be considered in MM, such as the Total Metabolic Tumor Volume, with this parameter being an index of the total volume of active disease in the PET FOV, and the total lesion glycolysis, reflecting the glycolytic phenotype of FLs.

To gain a PET negativity, according to the IMWG definition, each increase in tracer uptake at baseline or at previous PETs/CTs should disappear, or become inferior to the SUV of the MBP or of the surrounding normal tissue [1]. However, since many factors may influence the $\mathrm{SUV}_{\max }$ (first of all the uptake time), an attempt to standardize the cut-offs for positivity/negativity and achieve criteria for metabolic response has been made [14]. In this sense, previous findings revealed that the value of Deauville scores (DS), tested for the first time in MM [15], can be used for this purpose. Indeed, with this value being representative of the outcomes of the various patients, it has been proposed to define the PET complete metabolic response (CMR) after therapy, using the liver as a background (DS 4). The proposed PET metabolic response criteria are listed in Table 1. 
Table 1. Proposed refinement of the PET response criteria after therapy.

\begin{tabular}{cc}
\hline Pet Response after Therapy & Response Criteria \\
\hline CMR (complete metabolic response) & $\begin{array}{c}\text { Uptake } \leq \text { liver activity in BM sites and FLs previously involved } \\
\text { (including extra-medullary and para-medullary disease) (DS1-3). }\end{array}$ \\
\hline PMR (partial metabolic response) & $\begin{array}{c}\text { Decrease in the number and/or activity of BM/FLs present at baseline, } \\
\text { but persistence of lesion(s) with uptake >liver activity (DS 4 or 5). }\end{array}$ \\
\hline SMD (stable metabolic disease) & No significant change in BM/FLs compared to baseline. \\
\hline PMD (progressive metabolic disease) & New FLs compared to baseline consistent with myeloma. \\
\hline
\end{tabular}

Abbreviations: BM, bone marrow; DS, Deauville scale; FL(s), focal lesion(s).

When evaluating the 18F-FDG PET/CT imaging scans, false-positive/negative results may arise and should be excluded from the analysis. In particular, patients lacking the hexokinase enzyme (10-15\%) may have no 18F-FDG-avid PCs, [16], since this enzyme mediates FDG trapping in the cells; in such patients, FDG PET after treatment is not recommended [10,13], and an alternative tracer and/or tool should be considered. Moreover, false-negative results can be obtained soon after the use of high-dose steroids, due to the transient profound suppression of tumor metabolism and the competitive inhibition of FDG uptake from plasma cells related to increased glucose levels. On the contrary, the recent use of chemotherapy and/or growth factors, inducing bone marrow reconstitution, may result in false-positive findings. For these reasons, when possible, PET/CT should be performed at least one month after the use of all these agents.

Beyond 18F-FDG, preliminary investigations [17] have been carried out to test the sensitivity and specificity of new PET/CT tracers, targeting alternative metabolic pathways or different PC receptors that might prove to be valid molecular imaging biomarkers. PET imaging targeted to CXCR4 [18,19] and CD38 [20,21] has advanced into translational clinical trials, bringing us closer to powerful imaging options for myeloma. Antigenic-expressing tumor cells may be visualized through the use of radiolabelled antibodies, independently of metabolic processes, to obtain early and more accurate response assessments. For example, all MM cells express CD38, making them an excellent focus for targeted imaging and therapy. Daratumumab is an FDA-approved monoclonal antibody therapy for multiple myeloma that targets CD38. Conjugating daratumumab with the positron emitting radio-isotopes Copper-64 (64Cu) and Zirconium-89 (89Zr) has allowed the creation of immunoPET tracers for myeloma imaging [22,23]. 89Zr-daratumumab has demonstrated the ability to detect multiple myeloma in early clinical trials [22] which was overlooked by FDG PET/CT and other clinically standard imaging methods. Copper-64-daratumumab has been demonstrated as well to provide a safe whole-body imaging of MM [23], and the comparison with FDG is currently on-going. More advanced clinical trials for these immunoPET agents are planned. At the moment, however, it is not possible to gain any definitive conclusion, since the availability of these new tracers is still limited and no prognostic data and/or standard reporting have been gathered, not to mention the high heterogeneity of tumors among patients in specific targets.

\subsection{Clinical Studies}

PET-positive lesions after therapy have been largely linked to unfavorable prognosis. Indeed, a number of studies reported that, in the case of complete remission (CR), patients with FDG-PET/CT negativity after ASCT had a lower risk of progression or death with respect to those with metabolically active sites of the disease [23-29]. Moreover, in patients achieving MRD negativity by flow cytometry ( $10^{-5}$ sensitivity), imaging - either by PET/CT or whole body-diffusion weighted imaging-magnetic resonance (WB-DWI-MRI) - was positive in $12 \%$ of the cases, attributing to these patients a worse prognosis in terms of progression-free survival (PFS) [30]. On the other hand, patients reaching CR with MRD negativity during salvage therapy often displayed FLs (50\%). Additionally, it has recently been shown that patients obtaining PET FL normalization upon therapy have a comparable prognosis 
to those with no boosted metabolism at baseline, stressing the importance of prolonging the treatment until glucose metabolism is suppressed [28].

The complementarity between imaging (either FDG-PET/CT or WB-DWI-MRI) and BM techniques in defining the prognosis of patients was demonstrated by two prospective trials, applying flow cytometry as a BM technique with a sensitivity threshold of $10^{-4}$ [25] and $10^{-5}$ [30]. Moreover, very recently, the DS criteria to define PET/CT complete metabolic response have proven to be valid and applicable in newly diagnosed transplant-eligible MM (NDTEMM) patients, also confirming the complementarity with BM techniques [31].

On such a premise, 18F-FDG PET/CT currently is listed as the best imaging technique to evaluate and monitor metabolic response to therapy [12,13].

\section{Magnetic Resonance Imaging (MRI)}

The best tool to define the degree of BMPC infiltration, even prior to bone destruction, currently is the MRI, since this technique can visualize large volumes of BM and has a high sensitivity. As a result, this imaging technique is very useful in case of low tumor burden (e.g., in early stages or upon systemic therapy) $[10,13,32]$. Variations in MRI patterns may be attributable to the effects of therapy and may therefore be used to determine the efficacy of anti-myeloma treatment. In this sense, particular attention is given to MRI functional approaches, considered as the best option to evaluate disease after therapy, such as dynamic contrast-enhanced (DCE) and diffusion-weighted imaging (DWI) [33].

\subsection{Methods and Standardization}

MRI examines the water and fat content within tissue and is the most sensitive tool to detect the infiltration of BM in MM, with no radiation exposure [32,33]. An MM typical MRI pattern is the following: hypo-intensity in T1-weighted, hyper-intensity in T2-weighted with fat suppression in opposed phase imaging, and increased contrast-enhancement in T1-weighted sequences. Signal intensity is usually compared to the intervertebral disk as a reference. At least a $5 \mathrm{~mm}$ diameter is required to define a FL, also depending on the thickness of the MRI slice. The marrow involvement in MM may be classified into five different patterns: normal, focal, diffuse, combined focal, and diffuse and variegated or "salt and pepper" or variegate. The minimal FOV in MM is the axial skeleton (spine and pelvis), but more and more space is nowadays given to the whole-body protocol (WB-MRI). This technique is based on T1, T1 non-fat-saturated, and STIR sequences, usually not requiring contrast infusion; the total scan time for a whole-body image is generally less than $20 \mathrm{~min}$. Although contrast agents are not always necessary, thanks to the high resolution of non-enhanced MRI for the BM, they are usually based on gadolinium, which is relatively inert, except in case of renal failure, where it can cause a nephrogenic systemic fibrosis. As a further extension of MRI, DWI measures the movement of water molecules in the tissue, without the need for a contrast medium. Limited movements indicate high cellularity; on the contrary, an increase in movement reflects low cellularity and/or increased microcirculation. Semi-quantitative parameters, such as the apparent diffusion coefficient (ADC), correlate with a higher or lower cellularity [34], with the correlation between ADC and histological infiltration by BMPCs being clearly demonstrated.

The process of acquisition, interpretation, and reporting of WB-MRI is very important, thus allowing the use of this technique to assess response to therapy; an attempt in this regard has very recently been proposed [35].

\subsection{Clinical Studies}

Conventional MRI without contrast agents has been used to assess response after therapy in several clinical trials as addition to serological and BM-derived parameters. Two studies using MRI of the spine and pelvis and whole-body MRI in a total of 711 patients treated with high-dose chemotherapy protocols showed that residual lesions after completion of the most aggressive part of treatment had a significant adverse prognostic significance [36,37]. A later study comparing again axial MRI 
(including spine and pelvis) in 134 patients with multiple myeloma with PET/CT in the same patients treated in a multi-center trial showed that PET/CT was superior to MRI with regard to prognostic significance after therapy. The most likely explanation for this has been already examined in the first study of this kind, showing that the treatment response in MRI appears delayed, with focal lesions of myeloma disappearing slower because MRI is not able to differentiate between vital and necrotic tissue within preexisting osteolytic lesions [36]. Interestingly, a change in lesions into a more liquid or cystic appearance was associated with a higher rate of complete remissions but also with a higher proliferation index in gene expression profiling [38]. A further development of MRI is the DWI approach [34] that allows us to assess cellularity and microcirculation in the BM [39]. Recent studies suggest that whole-body DWI might be equivalent or even slightly superior to PET/CT in the assessment of the residual disease of multiple myeloma [40-46]. However, thus far, the assessment of metabolic response by means of DWIMRI is yet limited by the absence of a uniform interpretation of the results because of the differences in microenvironment and cellularity, which are associated both with age and necrosis, the latter being caused by ongoing treatments. Additionally, the best timing to assess response is still a matter of debate. An interdisciplinary group of clinicians and radiologists is currently working on this aspect to overcome this limitation [35].

\subsection{Choice of Imaging Technique for MRD Evaluation}

Thus far, the evaluation and monitoring of response to therapy in MM is entrusted to FDG-PET/CT, which is considered the best imaging technique for correlating post-treatment findings with outcomes $[1,10,12,13]$. $\mathrm{PET} / \mathrm{CT}$ is highly recommended in all patients that need to be tested for MRD after therapy. Indeed, this technique is capable of distinguishing cellular tissue from necrosis, which is crucial in these cases.

However, the FDG-based technique has some limitations, as discussed, and no homogeneous and prospective data are available on a comparison between FDG PRT/CT and WB-DWMRI in evaluating response to treatments. In case of negative imaging evaluation after therapy, serial evaluation until relapse can be recommended in patients with extra or para-medullary disease at diagnosis or in more advanced phases of the disease, when the risk of exclusive imaging-progression is higher. On the contrary, in patients with residual lesions, an annual follow-up can be recommended because of the high risk of early progression [29]; in such cases, functional imaging may be undoubtedly advantageous (Table 2).

Table 2. PET/CT and MRI in the evaluation of response to therapy.

\begin{tabular}{|c|c|c|}
\hline & PET/CT & Functional MRI \\
\hline Available studies & Large prospective independent studies. & $\begin{array}{l}\text { Several heterogeneous retrospective studies, in an } \\
\text { independent small series of patients, in different } \\
\text { disease phases. }\end{array}$ \\
\hline Results & $\begin{array}{l}\text { Predicts high risk of early progression for } \\
\text { patients with residual FLs. } \\
\text { Refines the prognosis of patients in } \\
\text { conventionally defined CR. } \\
\text { Defines the imaging MRD-negative } \\
\text { response category. } \\
\text { Is complementary to BM cellular or } \\
\text { molecular-based techniques. } \\
\text { - Contributes to defining the sustained } \\
\text { MRD-negative response category, associated } \\
\text { with the best patient outcomes. }\end{array}$ & $\begin{array}{l}\text { - Carries the higher reliability for diffuse } \\
\text { BM infiltration. } \\
\text { - } \quad \text { Demonstrated early changes during treatment. } \\
\text { - Apparently more sensitive than PET with FDG. }\end{array}$ \\
\hline
\end{tabular}

Abbreviations: PET/CT, positron emission tomography/computed tomography; MRI, magnetic resonance imaging; $\mathrm{CR}$, complete remission; $\mathrm{MRD}$, minimal residual disease; $\mathrm{BM}=$ bone marrow; FLs, focal lesions. 


\title{
4. Open Issues and Future Steps
}

Significant advances in MRD evaluation are based on the availability of novel functional imaging techniques, although many issues still need to be further investigated [47] (Table 3). Among these, it is an absolutely priority to achieve a complete standardization of guidelines for the acquisition, interpretation, and reporting of these imaging techniques, an attempt which is currently ongoing for both FDG PET/CT and WBMRI. Moreover, further investigation should be dedicated to the newer PET tracers and to DWIMRI, both needing to be correlated with clinical outcomes. DWIMRI images and PET/CT scans should also be prospectively compared, before and after therapy, to determine which technique is optimal for different patients and subgroups, and for different stages of disease both during and after treatment. Additionally and noteworthily, the concordance between complete metabolic response and flow or sequencing MRD negativity at the BM level need to be further explored, with different sensitivity thresholds $\left(10^{-5}-10^{-6}\right)$, as well as the complementary role of imaging techniques in detecting MRD, within or outside the BM, with either cellular or molecular-based tools. Similarly, the role of imaging techniques in determining a sustained MRD, or its loss, remains to be clearly defined, along with the identification of the optimal time points at which to achieve such an assessment. Finally, the impact of MRD-driven treatment strategies has not been defined yet. Upcoming prospective trials that apply these new techniques extensively and evaluate MRD both inside and outside the BM will finally address these open issues and optimize the use of imaging in daily clinical practice.

Table 3. Validated points and issues to be addressed by on-going trials for imaging-MRD evaluation.

\begin{tabular}{ll}
\hline Validated Points \\
\hline - $\quad$ Functional imaging techniques are the suggested tools for the assessment of imaging response. \\
- $\quad$ MRD by NGS or NGF and PET/CT are complementary. \\
- $\quad$ Process of the standardization of PET/CT and functional MRI currently ongoing.
\end{tabular}

Open issues

- $\quad$ Optimization of the use of new PET tracers and their correlation with survival outcomes.

- Correlation of DWIMRI with survival outcomes.

- $\quad$ Prospective comparison of PET/CT and functional MRI after therapy.

- Optimal timing of PET/CT and DWIMRI for the evaluation of response and during follow-up.

- Concordance between imaging and NGS/NGF MRD negativity, at different sensitivity thresholds.

- Contribution of imaging to the definition and loss of sustained MRD negativity.

- Impact of MRD assessment on treatment strategies.

\begin{abstract}
Abbreviations: WBLDCT, whole-body low-dose computed tomography; PET/CT, positron emission tomography/computed tomography; MRI, magnetic resonance imaging; SMM, smoldering multiple myeloma; MM, multiple myeloma; SP, solitary plasmocytoma; EMD, extramedullary disease; BM, bone marrow; MRD, minimal residual disease; DWI, diffusion-weighted imaging; NGS, next-generation sequencing; NGF, next-generation flow cytometry; PFS, progression-free survival; OS, overall survival; IMWG, international myeloma working group.
\end{abstract}

Author Contributions: All the authors substantially contributed to the paper. E.Z. and P.T. conceptualize the paper, searched the data, wrote the original draft. S.B. reviewed and edited the paper, supervised all the process. M.C. discussed the main topics, supervised all the process and reviewed the paper. All authors have read and agreed to the published version of the manuscript.

Funding: This research received no external funding.

Conflicts of Interest: E.Z. receives honoraria from Janssen, Bristol-Myers Squibb, Amgen, Takeda; P.T. receives honoraria from Janssen, Celgene, Bristol Myers Squibb, Amgen, Takeda, AbbVie, and Oncopeptides; M.C. receives honoraria from Janssen, Celgene, Amgen, Bristol-Myers Squibb, Takeda, AbbVie, Sanofi, and Adaptive Biotechnologies and is a member of Janssen's and Celgene's Speaker's Bureau; S.B. declares no potential conflict of interest. 


\section{References}

1. Kumar, S.; Paiva, B.; Anderson, K.C.; Durie, B.; Landgren, O.; Moreau, P.; Munshi, N.; Lonial, S.; Bladé, J.; Mateos, M.-V.; et al. International Myeloma Working Group consensus criteria for response and minimal residual disease assessment in multiple myeloma. Lancet Oncol. 2016, 17, e328-e346. [CrossRef]

2. Anderson, K.C.; Auclair, D.; Kelloff, G.J.; Sigman, C.C.; Avet-Loiseau, H.; Farrell, A.T.; Gormley, N.J.; Kumar, S.; Landgren, O.; Munshi, N.C.; et al. The Role of Minimal Residual Disease Testing in Myeloma Treatment Selection and Drug Development: Current Value and Future Applications. Clin. Cancer Res. 2017, 23, 3980-3993. [CrossRef] [PubMed]

3. Bladé, J.; De Larrea, C.F.; Rosiñol, L. Extramedullary involvement in multiple myeloma. Haematology 2012, 97, 1618-1619. [CrossRef] [PubMed]

4. Lu, Y.-Y.; Chen, J.-H.; Lin, W.-Y.; Liang, J.-A.; Wang, H.-Y.; Tsai, S.C.; Kao, C.-H. FDG PET or PET/CT for Detecting Intramedullary and Extramedullary Lesions in Multiple Myeloma: A systematic review and meta-analysis. Clin. Nucl. Med. 2012, 37, 833-837. [CrossRef]

5. Usmani, S.Z.; Mitchell, A.; Waheed, S.; Crowley, J.; Hoering, A.; Petty, N.; Brown, T.; Bartel, T.; Anaissie, E.; Van Rhee, F.; et al. Prognostic implications of serial 18-fluoro-deoxyglucose emission tomography in multiple myeloma treated with total therapy 3. Blood 2013, 121, 1819-1823. [CrossRef]

6. Ghimire, K.; Rajkumar, S.V.; Dispenzieri, A. Incidence and Survival Outcomes of Extramedullary Myeloma. Blood 2013, 122, 3141.

7. Rasche, L.; Chavan, S.S.; Stephens, O.W.; Patel, P.H.; Tytarenko, R.; Ashby, C.; Bauer, M.; Stein, C.; Deshpande, S.; Wardell, C.; et al. Spatial genomic heterogeneity in multiple myeloma revealed by multi-region sequencing. Nat. Commun. 2017, 8, 1-11. [CrossRef]

8. Rasche, L.; Angtuaco, E.J.; Alpe, T.L.; Gershner, G.H.; McDonald, J.E.; Samant, R.S.; Kumar, M.; Van Hemert, R.; Epstein, J.; Deshpande, S.; et al. The presence of large focal lesions is a strong independent prognostic factor in multiple myeloma. Blood 2018, 132, 59-66. [CrossRef]

9. Wahlin, A.; Holm, J.; Osterman, G.; Norberg, B. Evaluation of Serial Bone X-ray Examination in Multiple Myeloma. Acta Medica Scand. 1982, 212, 385-387. [CrossRef]

10. Zamagni, E.; Tacchetti, P.; Cavo, M. Imaging in multiple myeloma: How? When? Blood 2019, 133, $644-651$. [CrossRef]

11. Paiva, B.; Puig, N.; Cedena, M.T.; Cordon, L.; Vidriales, M.-B.; Burgos, L.; Flores-Montero, J.; Lopez-Anglada, L.; Gutierrez, N.; Calasanz, M.J.; et al. Impact of next generation flow minimal residual disease monitoring in multiple myeloma: Results from the PETHEMA/GEM2012 trial. Blood 2017, 130, 905.

12. Cavo, M.; Terpos, E.; Nanni, C.; Moreau, P.; Lentzsch, S.; Zweegman, S.; Hillengass, J.; Engelhardt, M.; Usmani, S.Z.; Vesole, D.H.; et al. Role of 18F-FDG positron emmission tomography/computed tomography in the diagnosis and management of multiple myeloma and other plasma cell dyscrasias: A consensus statement by the International Myeloma Working Group. Lancet Oncol. 2017, 18, e206-e217. [CrossRef]

13. Hillengass, J.; Usmani, S.; Rajkumar, S.V.; Durie, B.G.M.; Mateos, M.-V.; Lonial, S.; Joao, C.; Anderson, K.C.; García-Sanz, R.; Riva, E.; et al. International myeloma working group consensus recommendations on imaging in monoclonal plasma cell disorders. Lancet Oncol. 2019, 20, e302-e312. [CrossRef]

14. Nanni, C.; Versari, A.; Chauvie, S.; Bertone, E.; Bianchi, A.; Rensi, M.; Bellò, M.; Gallamini, A.; Patriarca, F.; Gay, F.; et al. Interpretation criteria for FDG PET/CT in multiple myeloma (IMPeTUs): Final results. IMPeTUs (Italian myeloma criteria for PET USe). Eur. J. Nucl. Med. Mol. Imaging 2018, 45, 712-719. [CrossRef]

15. Zamagni, E.; Nanni, C.; Dozza, L.; Carlier, T.; Tacchetti, P.; Versari, A.; Chauvie, S.; Gallamini, A.; Attal, M.; Gamberi, B.; et al. Standardization of 18F-FDG PET/CT according to Deauville criteria for metabolic complete response definition in newly diagnosed transplant eligible multiple myeloma (MM) patients: Joint analysis of two prospective randomized phase III trials. Blood 2018, 132, 257. [CrossRef]

16. Rasche, L.; Angtuaco, E.; McDonald, J.E.; Buros, A.; Stein, C.; Pawlyn, C.; Thanendrarajan, S.; Schinke, C.; Samant, R.; Yaccoby, S.; et al. Low expression of hexokinase-2 is associated with false-negative FDG-positron emission tomography in multiple myeloma. Blood 2017, 130, 30-34. [CrossRef]

17. Pandit-Taskar, N. Functional Imaging Methods for Assessment of Minimal Residual Disease in Multiple Myeloma: Current Status and Novel ImmunoPET Based Methods. Semin. Hematol. 2018, 55, $22-32$. [CrossRef] [PubMed] 
18. Herrmann, K.; Schottelius, M.; Lapa, C.; Osl, T.; Poschenrieder, A.; Hänscheid, H.; Lückerath, K.; Schreder, M.; Bluemel, C.; Knott, M.; et al. First-in-Human Experience of CXCR4-Directed Endoradiotherapy with 177Luand 90Y-Labeled Pentixather in Advanced-Stage Multiple Myeloma with Extensive Intra- and Extramedullary Disease. J. Nucl. Med. 2015, 57, 248-251. [CrossRef]

19. Lapa, C.; Herrmann, K.; Schirbel, A.; Hänscheid, H.; Lückerath, K.; Schottelius, M.; Kircher, M.; Werner, R.A.; Schreder, M.; Samnick, S.; et al. CXCR4-directed endoradiotherapy induces high response rates in extramedullary relapsed Multiple Myeloma. Theranostics 2017, 7, 1589-1597. [CrossRef]

20. Caserta, E.; Chea, J.; Minnix, M.; Poku, E.K.; Viola, D.; Vonderfecht, S.; Yazaki, P.; Crow, D.; Khalife, J.; Sanchez, J.F.; et al. Copper 64-labeled daratumumab as a PET/CT imaging tracer for multiple myeloma. Blood 2018, 131, 741-745. [CrossRef]

21. Ghai, A.; Maji, D.; Cho, N.; Chanswangphuwana, C.; Rettig, M.; Shen, D.; DiPersio, J.; Akers, W.; Dehdashti, F.; Achilefu, S.; et al. Preclinical Development of CD38-Targeted [89Zr]Zr-DFO-Daratumumab for Imaging Multiple Myeloma. J. Nucl. Med. 2017, 59, 216-222. [CrossRef] [PubMed]

22. Ulaner, G.A.; Sobol, N.B.; O’Donoghue, J.A.; Kirov, A.S.; Riedl, C.C.; Min, R.; Smith, E.; Carter, L.M.; Lyashchenko, S.K.; Lewis, J.S.; et al. CD38-targeted Immuno-PET of Multiple Myeloma: From Xenograft Models to First-in-Human Imaging. Radiology 2020, 295, 606-615. [CrossRef] [PubMed]

23. Zamagni, E.; Patriarca, F.; Nanni, C.; Zannetti, B.; Englaro, E.; Pezzi, A.; Tacchetti, P.; Buttignol, S.; Perrone, G.; Brioli, A.; et al. Prognostic relevance of 18-F FDG PET/CT in newly diagnosed multiple myeloma patients treated with up-front autologous transplantation. Blood 2011, 118, 5989-5995. [CrossRef] [PubMed]

24. Bartel, T.B.; Haessler, J.; Brown, T.L.Y.; Shaughnessy, J.J.D.; Van Rhee, F.; Anaissie, E.; Alpe, T.; Angtuaco, E.; Walker, R.; Epstein, J.; et al. F18-fluorodeoxyglucose positron emission tomography in the context of other imaging techniques and prognostic factors in multiple myeloma. Blood 2009, 114, 2068-2076. [CrossRef] [PubMed]

25. Moreau, P.; Attal, M.; Caillot, D.; Macro, M.; Karlin, L.; Garderet, L.; Facon, T.; Benboubker, L.; Escoffre-Barbe, M.; Stoppa, A.-M.; et al. Prospective Evaluation of Magnetic Resonance Imaging and [18F]Fluorodeoxyglucose Positron Emission Tomography-Computed Tomography at Diagnosis and Before Maintenance Therapy in Symptomatic Patients With Multiple Myeloma Included in the IFM/DFCI 2009 Trial: Results of the IMAJEM Study. J. Clin. Oncol. 2017, 35, 2911-2918. [CrossRef]

26. Beksac, M.; Gunduz, M.; Ozen, M.; Ozturk, S.M.B.; Kucuk, O.; Ozkan, E. Impact of PET-CT Response on Survival Parameters Following Autologous Stem Cell Transplantation Among Patients with Multiple Myeloma: Comparison of Two Cut-Off Values. Blood 2014, 124, 3983. [CrossRef]

27. Dimitrakopoulou-Strauss, A.; Hoffmann, M.; Bergner, R.; Uppenkamp, M.; Haberkorn, U.; Strauss, L.G. Prediction of Progression-Free Survival in Patients With Multiple Myeloma Following Anthracycline-Based Chemotherapy Based on Dynamic FDG-PET. Clin. Nucl. Med. 2009, 34, 576-584. [CrossRef]

28. Davies, F.E.; Rosenthal, A.; Rasche, L.; Petty, N.M.; McDonald, J.E.; Ntambi, J.A.; Steward, D.M.; Panozzo, S.B.; Van Rhee, F.; Zangari, M.; et al. Treatment to suppression of focal lesions on positron emission tomography-computed tomography is a therapeutic goal in newly diagnosed multiple myeloma. Haematology 2018, 103, 1047-1053. [CrossRef]

29. Zamagni, E.; Nanni, C.; Mancuso, K.; Tacchetti, P.; Pezzi, A.; Pantani, L.; Zannetti, B.; Rambaldi, I.; Brioli, A.; Rocchi, S.; et al. PET/CT Improves the Definition of Complete Response and Allows to Detect Otherwise Unidentifiable Skeletal Progression in Multiple Myeloma. Clin. Cancer Res. 2015, 21, 4384-4390. [CrossRef]

30. Rasche, L.; Alapat, D.; Kumar, M.; Gershner, G.; McDonald, J.; Wardell, C.P.; Samant, R.; van Hemert, R.; Epstein, J.; Williams, A.F.; et al. Combination of flow cytometry and functional imaging for monitoring of residual disease in myeloma. Leukemia 2019, 33, 1713-1722. [CrossRef]

31. Zamagni, E.; Nanni, C.; Gay, F.; Dozza, L.; Scalabrini, D.R.; Omedé, P.; Ribolla, R.; Galli, M.; Racca, M.; Zambello, R.; et al. MRD Evaluation by PET/CT According To Deauville Criteria Combined with bone marrow techniques in Newly Diagnosed Transplant Eligible Multiple Myeloma Patients enrolled in the Phase II FORTE Trial. Hematologica 2020, 134, 4321.

32. Dimopoulos, M.-A.; Hillengass, J.; Usmani, S.; Zamagni, E.; Lentzsch, S.; Davies, F.E.; Raje, N.; Sezer, O.; Zweegman, S.; Shah, J.; et al. Role of Magnetic Resonance Imaging in the Management of Patients With Multiple Myeloma: A Consensus Statement. J. Clin. Oncol. 2015, 33, 657-664. [CrossRef] [PubMed] 
33. Terpos, E.; Kleber, M.; Engelhardt, M.; Zweegman, S.; Gay, F.; Kastritis, E.; Van De Donk, N.W.; Bruno, B.; Sezer, O.; Broijl, A.; et al. European Myeloma Network Guidelines for the Management of Multiple Myeloma-related Complications. Haematology 2015, 100, 1254-1266. [CrossRef]

34. Koutoulidis, V.; Fontara, S.; Terpos, E.; Zagouri, F.; Matsaridis, D.; Christoulas, D.; Panourgias, E.C.; Kastritis, E.; Dimopoulos, M.A.; Moulopoulos, L.A. Quantitative Diffusion-weighted Imaging of the Bone Marrow: An Adjunct Tool for the Diagnosis of a Diffuse MR Imaging Pattern in Patients with Multiple Myeloma. Radiology 2017, 282, 484-493. [CrossRef]

35. Messiou, C.; Hillengass, J.; Delorme, S.; Lecouvet, F.E.; Moulopoulos, L.A.; Collins, D.J.; Blackledge, M.D.; Abildgaard, N.; Østergaard, B.; Schlemmer, H.-P.; et al. Guidelines for Acquisition, Interpretation, and Reporting of Whole-Body MRI in Myeloma: Myeloma Response Assessment and Diagnosis System (MY-RADS). Radiology 2019, 291, 5-13. [CrossRef]

36. Walker, R.; Barlogie, B.; Haessler, J.; Tricot, G.; Anaissie, E.; Shaughnessy, J.D.; Epstein, J.; Van Hemert, R.; Erdem, E.; Hoering, A.; et al. Magnetic Resonance Imaging in Multiple Myeloma: Diagnostic and Clinical Implications. J. Clin. Oncol. 2007, 25, 1121-1128. [CrossRef] [PubMed]

37. Hillengass, J.; Ayyaz, S.; Kilk, K.; Weber, M.-A.; Hielscher, T.; Shah, R.; Hose, D.; Delorme, S.; Goldschmidt, H.; Neben, K. Changes in magnetic resonance imaging before and after autologous stem cell transplantation correlate with response and survival in multiple myeloma. Haematologica 2012, 97, 1757-1760. [CrossRef]

38. Merz, M.; Hielscher, T.; Mai, E.K.; Seckinger, A.; Hose, D.; Jauch, A.; Sauer, S.; Luntz, S.; Bertsch, U.; Raab, M.S.; et al. Cystic transformation of focal lesions after therapy is associated with remission but adverse outcome in myeloma. Blood Cancer J. 2019, 9, 1-5. [CrossRef]

39. Le Bihan, D.; Breton, E.; Lallemand, D.; Aubin, M.L.; Vignaud, J.; Laval-Jeantet, M. Separation of diffusion and perfusion in intravoxel incoherent motion MR imaging. Radiology 1988, 168, 497-505. [CrossRef]

40. Pawlyn, C.; Fowkes, L.; Otero, S.; Jones, J.R.; Boyd, K.D.; Davies, F.E.; Morgan, G.J.; Collins, D.J.; Sharma, B.; Riddell, A.; et al. Whole-body diffusion-weighted MRI: A new gold standard for assessing disease burden in patients with multiple myeloma? Leukemia 2016, 30, 1446-1448. [CrossRef]

41. Messiou, C.; Giles, S.; Collins, D.J.; West, S.; Davies, F.E.; Morgan, G.J.; DeSouza, N.M. Assessing response of myeloma bone disease with diffusion-weighted MRI. Br. J. Radiol. 2012, 85, e1198-e1203. [CrossRef] [PubMed]

42. Hillengass, J.; Merz, M.; Delorme, S. Minimal residual disease in multiple myeloma: Use of magnetic resonance imaging. Semin. Hematol. 2018, 55, 19-21. [CrossRef] [PubMed]

43. Giles, S.L.; Messiou, C.; Collins, D.J.; Morgan, V.A.; Simpkin, C.J.; West, S.; Davies, F.E.; Morgan, G.J.; DeSouza, N.M. Whole-Body Diffusion-weighted MR Imaging for Assessment of Treatment Response in Myeloma. Radiology 2014, 271, 785-794. [CrossRef]

44. Latifoltojar, A.; Hall-Craggs, M.; Rabin, N.; Popat, R.; Bainbridge, A.; Dikaios, N.; Sokolska, M.; Rismani, A.; D'Sa, S.; Punwani, S.; et al. Whole body magnetic resonance imaging in newly diagnosed multiple myeloma: Early changes in lesional signal fat fraction predict disease response. Br. J. Haematol. 2016, 176, 222-233. [CrossRef] [PubMed]

45. Dutoit, J.C.; Claus, E.; Offner, F.; Noens, L.; Delanghe, J.; Verstraete, K. Combined evaluation of conventional MRI, dynamic contrast-enhanced MRI and diffusion weighted imaging for response evaluation of patients with multiple myeloma. Eur. J. Radiol. 2016, 85, 373-382. [CrossRef]

46. Lacognata, C.; Crimì, F.; Guolo, A.; Varin, C.; De March, E.; Vio, S.; Ponzoni, A.; Barilà, G.; Lico, A.; Branca, A.; et al. Diffusion-weighted whole-body MRI for evaluation of early response in multiple myeloma. Clin. Radiol. 2017, 72, 850-857. [CrossRef]

47. Moreau, P.; Zamagni, E. MRD in multiple myeloma: More questions than answers? Blood Cancer J. 2017, 7, 639. [CrossRef]

Publisher's Note: MDPI stays neutral with regard to jurisdictional claims in published maps and institutional affiliations. 